\title{
Generalization of Intensity-Duration-Frequency Formula for Litani River Basin-Lebanon
}

\author{
Hilal Obeid ${ }^{1} \&$ Mohamed Elkholy ${ }^{2}$ \\ ${ }^{1}$ Ph.D. Candidate, Civil and Environmental Engineering Department, Faculty of Engineering, Beirut Arab \\ University, Lebanon \\ ${ }^{2}$ Assistant Professor, Civil and Environmental Engineering Department, Faculty of Engineering, Beirut Arab \\ University, Lebanon \\ Correspondence: Hilal Obeid, Civil and Environmental Engineering Department, Faculty of Engineering, Beirut \\ Arab University, Lebanon.
}

Received: February 2, 2021; Accepted: February 25, 2021; Published: February 27, 2021

\begin{abstract}
The objective of this paper is the generalization of IDF-formula for Litani River Basin-Lebanon following Bell (1969) \& Chen (1969). Generalization is the use of a basic rainfall intensity at specific duration and frequency (i.e $\mathrm{P}_{1 \mathrm{hr}}, \mathrm{T}=10$ years) to get the depth or Intensity of rainfall at different durations and return periods. This method is beneficial in developing countries where short duration rainfall data are not currently available. In this paper, a generalized IDF formula was developed based on a basic value of rainfall intensity as 100-year and 24 hours . Five available weather stations at Litani River Basin in Lebanon were used to gather different metrological conditions which may represent typical Mediterranean basin as well.

In the first step of the research the SCS Type II distribution was used to derive short duration rainfall data from the available daily records. The derived data was used to get the Intensity-Duration Ratios $\left[\frac{I_{d}^{T}}{I_{24}^{T}}\right] \&$ the Intensity Frequency ratios $\left[\frac{I_{d}^{T}}{I_{d}^{100}}\right]$ at each of the five stations upon which average ratios were obtained and optimized using least square method to get the "Chen" generalized formula parameters: $I_{d}^{T}=I_{24-h r}^{100 Y r s} \frac{A}{(d+B)^{C}}(\lambda \ln T+H)$. The intensity values obtained by the generalized formula were validated by comparing to the original values which was obtained previously using frequency analysis. The results show a strong correlation with Average Mean Percentage Error "MAPE" of $4.38 \%$ at Tyre, $1.63 \%$ at Qaroun, $1.86 \%$ at Lebaa, $1.82 \%$ at Zahle and $3.98 \%$ at Reyak station.

The lack of adequate weather stations as well as sub-hourly and hourly rainfall data means that it is not possible to predict rainfall intensities over long return periods at several locations in Lebanon. In the second step of this paper, sub-hourly rainfall records, collected using four raingauages for a period of 3 years, were used to derive a generalized IDF formula based on $I_{24}^{2}(\mathrm{~d}=24 \mathrm{hrs}, \mathrm{T}=2$ years $)$ rainfall intensity. Because the intensity-duration and the intensity-frequency ratios obtained from 3 years' data are not fully representative for the ratios which Bell \& Chen equations were built on (more than 20 years of historical records), the obtained generalized formula, which is based on only 3 years' data, was considered to be correlated to the formula obtained in step 1 (based on 23 years daily records \& SCS Type II distribution) by 3 function as follows:
\end{abstract}

$$
I_{d}^{T}=\mathrm{F} 1 * I_{24-h r}^{2 Y r s} \mathrm{~F} 2 * \frac{a}{(d+b)^{c}} \mathrm{~F} 3 *(\mu \ln T+h) .
$$

Where F1, F2 \& F3 represent the correlation functions between $I_{24}^{2} \& I_{24}^{100}$ generalized IDF equations. 
- $\quad \mathrm{F} 1=\frac{I_{24}^{100}}{I_{24}^{2}}:$ is the average ratio between the intensity $\mathrm{I}(\mathrm{T}=100$ Years, $\mathrm{d}=24$ hours $)$ and the measured raingauge intensity $\mathrm{I}(\mathrm{T}=2$ Years, $\mathrm{d}=24$ hours $)$ at each station.

- $\quad$ F2 represent the relationship between the intensity-duration ratio obtained from 3 years' gauge data and that obtained from 23 years recording data (using SCS Type II distribution).

$\frac{I_{d}^{T}}{I_{24}^{T}}($ Average ratio of 23 years data $)=F 2 * \frac{I_{d}^{T}}{I_{24}^{T}}(2$ years gauges data $)=F 2 * \frac{a}{(d+b)^{c}}$

- $\quad$ F3 represent the relationship between intensity-frequency ratios obtained from 3 years' gauge data and that obtained from 23 years recording data (using SCS Type II Distribution).

$\frac{I_{d}^{T}}{I_{d}^{2}}(2$ years gauges data $)=F 3 * \frac{I_{d}^{T}}{I_{d}^{100}}($ Average ratio of 23 years data $)=F 3 *(\mu \ln T+h)$

The results show a strong correlation with Average Mean Percentage Error "MAPE" of $6.3 \%$ at Tyre, 3.67\% at Qaroun, $4.12 \%$ at Lebaa, $4.21 \%$ at Zahle and $8.62 \%$ at Reyak station.

This method is beneficial in developing countries through which 3 years of available sub-hourly and hourly rainfall data could be used to develop IDF relationships.

Keywords: Intensity Duration Frequency Curves (IDF Curves), Generalized IDF Formula, Litani River

\section{Introduction}

Rainfall Intensity-Duration-Frequency "IDF" relationship is a mathematical relationship between the rainfall intensity, $i$ (more precisely, the mean intensity $\mathrm{mm} / \mathrm{hr}$ ), the duration, $d$ (min or hours), and the return period, $T$ (the annual frequency of exceedance). The IDF relation is represented mathematically as follows:

$$
I=f(T, d)
$$

A general empirical equation for most of the IDF curves presented by many researchers; Talbot (1881), Bernard (1932), Kimijima and Sherman (1931) may be written as:

$$
\mathrm{i}=\frac{\mathrm{A}}{(\mathrm{d}+\mathrm{B})^{\mathrm{C}}}
$$

where, $a, b$ and $c$ are nonnegative coefficients (These four empirical equations and others are found in the literature of Hydrology applications -Chow et al.,1988).

Based on the above general equation, many authors have developed generalized IDF equations along the world. A generalized IDF equation using the one hour, 10 years rainfall depths; $\mathrm{P}_{1}^{10}$, as an index was proposed by Bell (1969). Further a generalized IDF formula, for any location in the United States using three base rainfall depths: $P_{1}^{10}, P_{24}^{10}, P_{1}^{100}$, was developed by Chenglung Chen (1983), which describe the geographical variation of rainfall.

Additional generalized IDF relationships for high intensity short duration rainfall and return period was developed by Bell as:

$$
\begin{aligned}
& \frac{\mathrm{P}_{\mathrm{d}}^{\mathrm{T}}}{\mathrm{P}_{60}^{\mathrm{T}}}=0.54 \mathrm{~d}^{0.25}+0.50(5 \mathrm{~min}<d<120) \\
& \frac{\mathrm{P}_{\mathrm{d}}^{\mathrm{T}}}{\mathrm{P}_{\mathrm{d}}^{10}}=0.21 \ln \mathrm{T}+0.52(2 \leq \mathrm{T}<100 \text { years })
\end{aligned}
$$

Which may be combined together to give an estimate of the precipitation, $\mathrm{P}(\mathrm{d}, \mathrm{T})$ for any rainfall duration at any return period relative to a pre-specified base precipitation, $\mathrm{P}\left(\mathrm{d}^{\prime}, \mathrm{T}^{\prime}\right)$.

$$
\frac{\mathrm{P}_{d}^{\mathrm{T}}}{\mathrm{P}_{\mathrm{d} \prime}^{\mathrm{T}}}=\mathrm{f}_{1}(\mathrm{~d}) \mathrm{f}_{2}(\mathrm{~T})
$$

Where, $T$ is the recurrence interval (year), $d$ the rainfall duration; $T$ ' is a constant return period (year) as the base value; $d$, a constant rainfall duration as the base value. $I_{d}^{T}$ is the rainfall intensity with a $T$ year return period and $\mathrm{d}$ hour rainfall duration. $\mathrm{I}_{\mathrm{d} \prime}^{\mathrm{T}}$ ' is the rainfall intensity with a base $\mathrm{T}^{\prime}$ years return period and a base $\mathrm{d}^{\prime}$ hours rainfall duration. $f_{1}(T)$ is a function of only return period $T$ and assumed to be the ratio of $I_{d}^{T}$ to $I_{d}^{T \prime}$. Here the function 
does not depend on the duration $d . f_{2}(d)$ is a function of only duration $d$ and assumed to be the ratio of $I_{d}^{T}$ to $I_{d}^{T}$. Here the function does not depend on the return period $\mathrm{T}$.

Equation (1.5) may be further expanded and written as (after Bell -1969, Chen -1983 and Koutsoyiannis et al.1998):

$$
\mathrm{I}_{\mathrm{d}}^{\mathrm{T}}=\mathrm{I}_{\mathrm{d}^{\prime}}^{\mathrm{T}^{\prime}} * \frac{A}{(\mathrm{~d}+\mathrm{B})^{\mathrm{C}}} *(\lambda \ln \mathrm{T}+\mathrm{H})
$$

The equation (1.6) is generalized formula of rainfall intensity frequency formula using base rainfall intensity with d' hour's rainfall duration, and T' years return period.

Based on the above, many hydrologists derived and developed generalized IDF relationships for different regions along the world.

\section{Study Area}

Situated within the boundaries of Lebanon, Litani River runs for about $170 \mathrm{~km}$ through Bekaa Valley in a southwesterly direction to meet the Mediterranean Sea near Tyre City (see Figure. 1.1).

It forms a catchment of around $2,175 \mathrm{~km}^{2}$ area that is divided into two sub-basins by Qaraoun dam which was constructed in 1960s for water storage and electricity generation. The Upper Basin stretches, before the dam, with an approximate area of $1500 \mathrm{~km}^{2}$ and altitudes that range from 800 to $1000 \mathrm{~m}$. While the lower basin, just downstream the dam, has an area of around $600 \mathrm{~km}^{2}$ and has a steep slope ranging from $800 \mathrm{~m}$ to the sea level at its outlet in approximately $60 \mathrm{~km}$. Five available weather stations, representing the different climatological conditions of the country, are distributed along both the Upper and Lower River Basins. Data from these five stations are being analyzed to help in estimating a generalized IDF relationship applicable for Lebanon.

The stations are: Tyre, Lebaa, Qaroun, Zahle and Reyak.

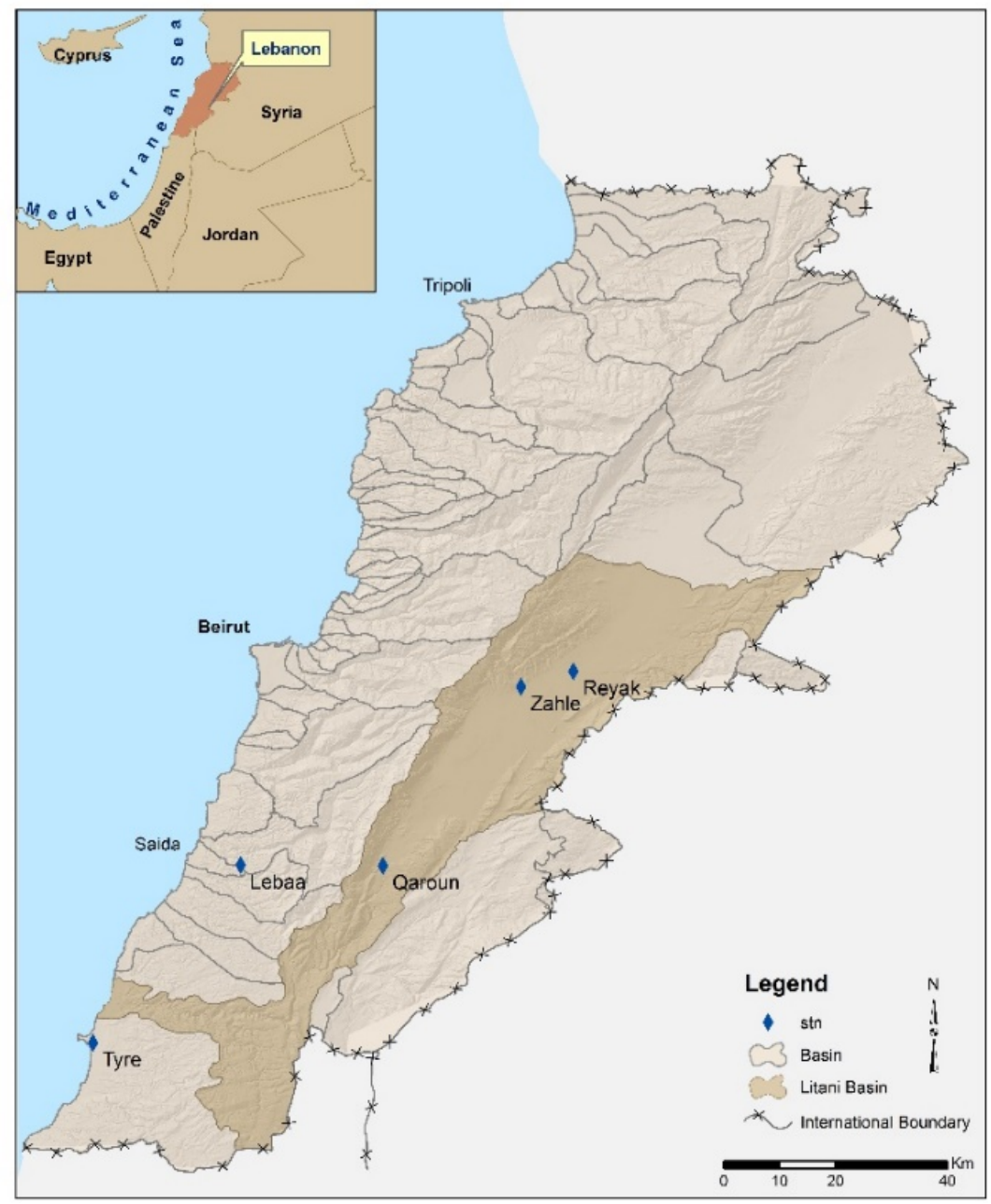

Figure 1.1 Litani River Basin and Weather Stations 


\section{Data Collection}

Daily rainfall data, from the period of 1998 to 2020, were collected from Beirut Airport Weather Forecast and Lebanese Agricultural Research Institute (LARI) for five stations represent the different basin metrological conditions. The annual maximum daily rainfall records were taken out from the available data (Table1.1).

Like most developing countries, Lebanon lacks the historical rainfall data of short durations and consequently the IDF curves. In order to derive short rainfall data from the available daily records; SCS-Type II method were used to derive sub-hourly and hourly rainfall data.

Table 1.1 Maximum daily rainfall $(\mathrm{mm})$ at the five stations in Litani River Basin-Lebanon

\begin{tabular}{llllll}
\hline Year & Tyre & Lebaa & Qaroun & Zahle & Reyak \\
\hline 1998 & 38.2 & - & - & - & 90 \\
1999 & 45 & 62 & 91 & 41 & 83.12 \\
2000 & 57 & 59.7 & 82 & 38.2 & 46.6 \\
2001 & 64.6 & 59.3 & 46 & 44.7 & 41.5 \\
2002 & 55.4 & 53 & 74 & 61.8 & 52.5 \\
2003 & 58.4 & 50.7 & 71.6 & 61.8 & 56 \\
2004 & 49.2 & 68.3 & 81.6 & 54.8 & 64.5 \\
2005 & 34.5 & 68.5 & 72.9 & 44.8 & 48.5 \\
2006 & 54.8 & 60.4 & 112.2 & 36.8 & 34 \\
2007 & 48.4 & 75 & 64.6 & 47.2 & 54.7 \\
2008 & 33.2 & 53 & 62.6 & 30.2 & 26.4 \\
2009 & 58.5 & 86 & 117.6 & 60 & 71.6 \\
2010 & 80 & 105 & 95.8 & 50 & 73.6 \\
2011 & 37 & 76 & 53.4 & 48.4 & 32 \\
2012 & 60.8 & 83.2 & 61.6 & 69.6 & 57.4 \\
2013 & 45 & 95 & 89.5 & 77 & 58.4 \\
2014 & 52 & 41 & 60.6 & 32.8 & 42 \\
2015 & 49 & 51 & 70.8 & 48 & 42.4 \\
2016 & 46 & 69 & 60.8 & 57.6 & 45.4 \\
2017 & 48 & 48 & 64.6 & 39.2 & 40 \\
2018 & 51 & 64 & 55.4 & 48.8 & 48.6 \\
2019 & 52 & 56.2 & 92.8 & 41 & 52.6 \\
2020 & 41 & 39.4 & - & 32.4 & 36.2 \\
\hline Mean & 50.4 & 64.7 & 75.3 & 48.5 & 52.1 \\
Std & 10.6 & 21.2 & 28.2 & 15.7 & 16.1 \\
\hline
\end{tabular}

\section{Methodology}

The objectives of this research is to establish two general IDF equations, for Litani River Basin, based on prespecified rainfall depths $\boldsymbol{P}_{\mathbf{2 4}}^{\mathbf{1 0 0}}$ (d=24 hours, T=100 years) and $\boldsymbol{P}_{\mathbf{2 4}}^{\mathbf{2}}$ (d=24 hours, T=2 years). These two equations can be used in other watersheds where either adequate historical daily records or few daily records are available.

\section{i. Establishment of General IDF Equation based on $P_{24}^{100}$.}

- Calculate Intensity-Duration Ratio to find the parameters A, B \& C of $F_{I}(d) ; \frac{I_{d}^{T}}{I_{24}^{T}}=\frac{A}{(d+B)^{C}}$.

- Calculate Intensity-Frequency Ratio to find the parameters $\lambda \& \mathrm{H}$ of $\quad F_{2}(T) ; \frac{I_{d}^{T}}{I_{d}^{100 Y Y_{s}}}=(\lambda * \ln T+H)$.

- Combine the above two equations in one general equation with $\boldsymbol{P}_{\mathbf{2 4}}^{\mathbf{1 0 0}}$ as index, $\frac{\mathrm{I}_{\mathrm{d}}^{\mathrm{T}}}{\mathrm{I}_{\mathrm{d} \prime}^{\prime \prime}}=F_{1}(d) F_{2}(T)$.

where, A, B C,$\lambda \& \mathrm{H}$ are parameters of empirical equations derived from 20 years' historical daily records. 


\section{ii. Establishment of General IDF Equation based on $P_{24}^{2}$.}

- Calculate Intensity-Duration Ratio to find the parameters a, b \& c of $f_{l}(d) ; \frac{I_{d}^{T}}{I_{24}^{T}}=\frac{a}{(d+b)^{c}}$.

- Calculate Intensity-Frequency Ratio to find the parameters $\mu \&$ h of $f_{2}(T) ; \frac{I_{d}^{T}}{I_{d}^{100 \mathrm{Yrs}}}=(\mu * \ln T+h)$.

- Combine the above two equations in one general equation, with $\boldsymbol{P}_{24}^{2}$ as index, $\frac{\mathrm{I}_{\mathrm{d}}^{\mathrm{T}}}{\mathrm{I}_{\mathrm{d} \prime}^{\mathrm{T} \prime}}=f_{1}(\mathrm{~d}) f_{2}(\mathrm{~T})$.

- $\quad$ Find a correlation functions between the both general equations to derive the general IDF equation based on only 3 years' daily records.

where $\mathrm{a}, \mathrm{b}, \mathrm{c}, \mu \& \mathrm{~h}$ are parameters of empirical equations derived from only 3 years daily records.

\section{Results and Analysis}

\section{i. Generalized IDF Formula based on 23 years' records as $d=24$ hours $\&$ T=100 Years.}

\section{- Calculate the Intensity-Duration Ratios}

The rainfall intensity-duration ratios $\frac{I_{d}^{T}}{I_{24 h r}^{T}}$ are usually calculated for each value of return periods. The calculations are made in order to obtain the average value of ratios for the duration considered. SCS distribution is used to derive the unavailable sub-hourly and hourly rainfall data.

Table 1.2 lists the values of rainfall intensity-duration ratios. The ratios $F_{1}(d)$ was fitted by Sherman Equation (1932) using least square method. The obtained parameters are $\mathrm{A}=5470, \mathrm{~B}=68.06$ and $\mathrm{C}=1.18$ with correlation coefficient value $\mathrm{R}^{2}=0.97$. Figure 1.2 shows relationship between rainfall intensity ratios, $F 1(d)$ and duration, d, of the five stations in Litani River Basin.

$$
F 1(d)=\frac{I_{d}^{T}}{I_{24 h r}^{T}}=\frac{5470}{(d+68.06)^{1.18}}
$$

Table 1.2 Rainfall Intensity-Duration Ratios $I_{d}^{T} / I_{24-h r}^{T}$ average for all durations $(\mathrm{d}=0.25,0.5,1,3,6,12,18$ \& 24 hours)

\begin{tabular}{lllllllll}
\hline All Stations (d in hours) & 0.25 & 0.5 & 1 & 3 & 6 & 12 & 18 & 24 \\
\hline Average $I_{d}^{T} / I_{24-h r}^{T}$ & 29.36 & 24.24 & 17.63 & 7.98 & 4.21 & 2.08 & 1.36 & 1.0 \\
\hline
\end{tabular}

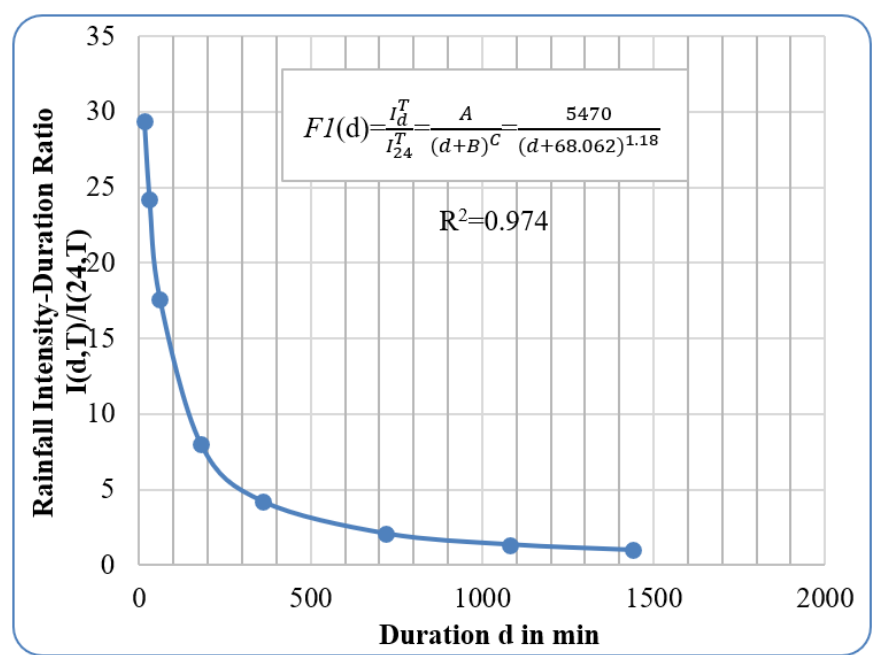

Figure 1.2 Rainfall Intensity-Duration Ratios and Duration. This graph was fitted by Sherman Equation (1.7) to get the parameters A, B \& C 


\section{- Calculate the Intensity-Frequency Ratios}

The procedure to obtain the parameters $\lambda \& H$ of equation (1.8), is described in the following 3 steps:

$$
F 2(T)=\frac{I_{d}^{T}}{I_{d}^{100 Y r s}}=(\lambda * \ln T+\mathrm{H})
$$

- The average rainfall intensity $I_{d}^{T}$, for the five stations, were calculated for each duration, $(\mathrm{d}=15 \mathrm{~min}, 30 \mathrm{~min}$, $1 \mathrm{hr}, 3 \mathrm{hrs}, 6 \mathrm{hrs}, 12 \mathrm{hrs}, 18 \mathrm{hrs}$ and $24 \mathrm{hrs}$ ) at return periods T=2, 5, 10, 25, $50 \& 100$ years.

- $\quad$ Figure 1.3 shows the average rainfall intensity values at each return period versus the average rainfall intensity at 100-yr return period. The slope of each line is the Intensity-Frequency ratio at each recurrence interval, T. Table 1.3 shows the average rainfall intensity-frequency ratios and standard deviations for each return period.

- $\quad$ Figure 1.4 represents that relationship between rainfall intensity (I) and Frequency (T) of the 5 stations through which the parameter $\lambda=0.1182$ (slope of linear regression relationship between the log-transformed values of return periods) and $H=0.4619$ were obtained with correlation coefficient value $\mathrm{R}^{2}=0.99$.

$$
F 2(T)=\frac{I_{d}^{T}}{I_{d}^{100 Y r s}}=(0.1182 * \ln T+0.4619)
$$

Table 1.3 Rainfall Intensity-Frequency Ratios $\frac{I_{d}^{T}}{I_{d}^{100 Y r s}}$ average for all return periods.

\begin{tabular}{lllllll}
\hline \multirow{2}{*}{ Station } & \multicolumn{7}{l}{ Return Periods - T Years } & \multicolumn{3}{l}{} \\
\cline { 2 - 7 } Tyre & $\mathbf{2}$ & $\mathbf{5}$ & $\mathbf{1 0}$ & $\mathbf{2 5}$ & $\mathbf{5 0}$ & $\mathbf{1 0 0}$ \\
\cline { 2 - 7 } Lebaa & 0.582 & 0.694 & 0.768 & 0.862 & 0.931 & 1.000 \\
Qaroun & 0.528 & 0.655 & 0.738 & 0.844 & 0.922 & 1.000 \\
Zahle & 0.538 & 0.666 & 0.748 & 0.850 & 0.925 & 1.000 \\
Reyak & 0.534 & 0.659 & 0.741 & 0.846 & 0.923 & 1.000 \\
Average & 0.483 & 0.621 & 0.713 & 0.829 & 0.915 & 1.000 \\
St. Dev. & $\mathbf{0 . 5 3 3}$ & $\mathbf{0 . 6 5 9}$ & $\mathbf{0 . 7 4 2}$ & $\mathbf{0 . 8 4 6}$ & $\mathbf{0 . 9 2 3}$ & $\mathbf{1 . 0 0 0}$ \\
\hline
\end{tabular}

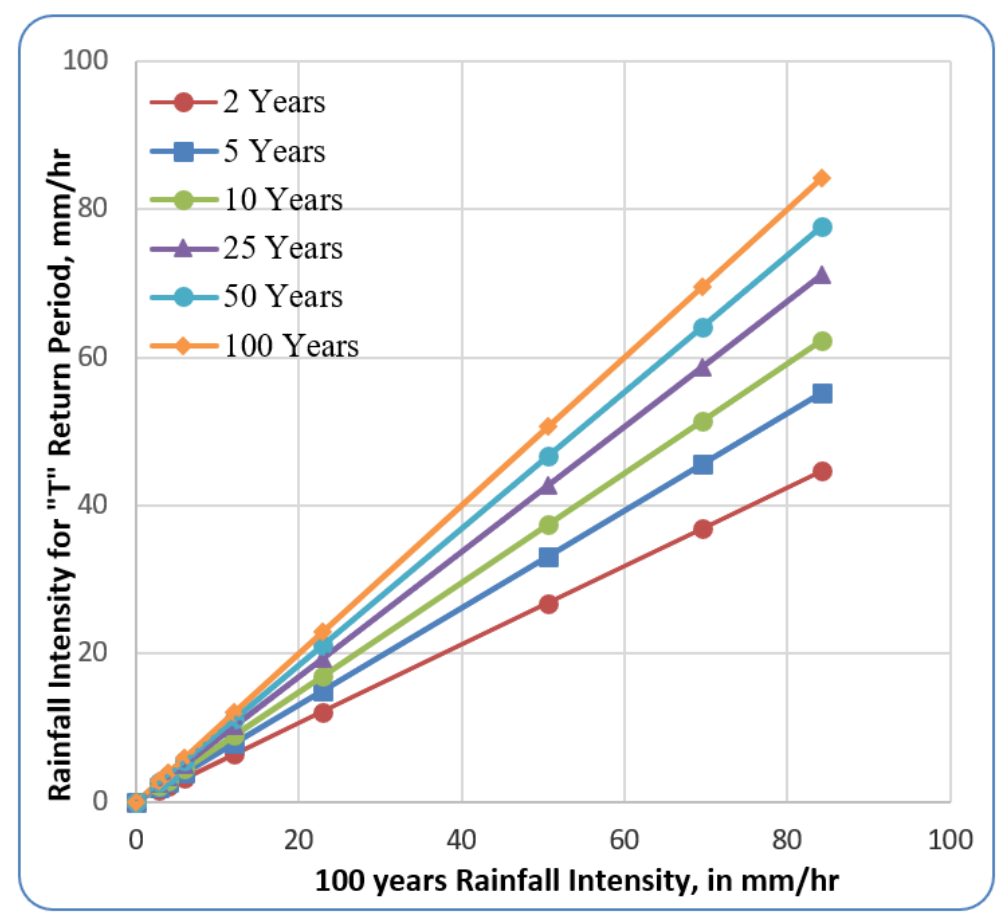

Figure 1.3 Rainfall Intensity-Frequency Ratios 


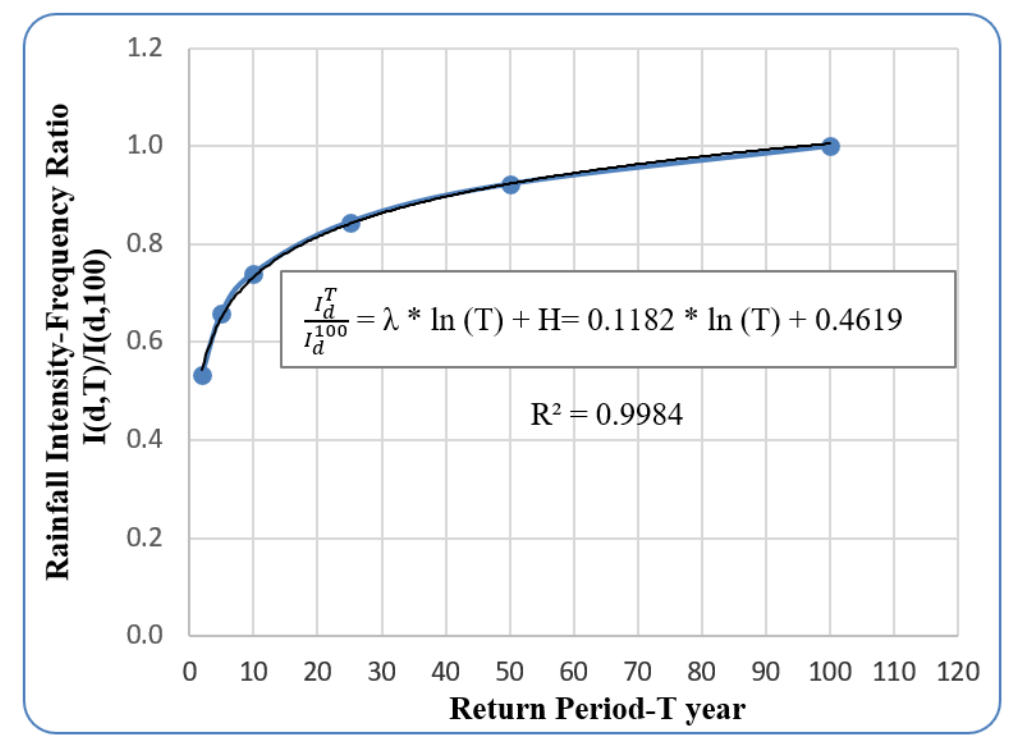

Figure 1.4 Rainfall Intensity-Frequency Ratios and Return periods. This graph was fitted by Bell generalized formula (1.8) to get the parameters $\lambda \& H$

\section{- Combining the Equations (Bell, Chen \& Sherman) in one General IDF Formula.}

After combining Equations (1.5), (1.7) and (1.9), the generalized formula of rainfall intensity frequency based on $I_{24 h r}^{100 Y r s}$ rainfall intensity can be written as equation 1.10 .

$$
I_{d}^{T}=I_{24}^{100} * \frac{5470}{(d+68.06)^{1.18}} *(0.1182 \ln T+0.4619)
$$

For example, at Tyre station the rainfall intensity obtained by statistical method I( $24-\mathrm{hr}, 100-\mathrm{yr})$ is $2.26 \mathrm{~mm} / \mathrm{hr}$, thus the IDF curves can be derived (using Generalized Formula based on $I_{24}^{100}$ ) by evaluating the value of $I_{24 \mathrm{hr}}^{100 \mathrm{rs}}$ $=2.26$ in Eq. (1.10).

\section{ii. Generalized IDF Formula based on 3 years' records as $\mathrm{d}=\mathbf{2 4}$ hours $\& \mathrm{~T}=\mathbf{2}$ Years.}

Similar approach like the one in the first step (i) is carried on in this section but using actual measurements of 3yrs records rather than using 23 -yrs historical daily records with sub-hourly \& hourly data derived using SCSType II Rainfall distribution.

\section{- Calculate the Intensity-Duration Ratios}

Here, the rainfall intensity-duration ratios $\frac{I_{d}^{2}}{I_{24 h r}^{2}}$ were calculated for all extreme rainfall storms measured during 3 years at each weather station. Table 1.4 shows the ratios at each station, the average ratios and the standard deviations. After fitting the average ratios to Sherman equation, the obtained parameters are $a=31.21, b=-0.876$ and $\mathrm{c}=0.4605$ with correlation coefficient value $\mathrm{R}^{2}=0.99$.

$$
f 1(d)=\frac{I_{d}^{2}}{I_{24 h r}^{2}}=\frac{31.21}{(d-0.876)^{0.4605}}
$$


Table 1.4 Rainfall Intensity-Duration Ratios $\frac{I_{d}^{2}}{I_{24 h r}^{2}} \quad$ average for all extreme storms during a period of T=2Years

\begin{tabular}{lllllllll}
\hline \multirow{2}{*}{ Station } & \multicolumn{2}{l}{ Duration Hours } & & & & & & \\
\cline { 2 - 9 } Tyre & $\mathbf{0 . 2 5}$ & $\mathbf{0 . 5 0}$ & $\mathbf{1 . 0 0}$ & $\mathbf{3 . 0 0}$ & $\mathbf{6 . 0 0}$ & $\mathbf{9 . 0 0}$ & $\mathbf{1 2 . 0 0}$ & $\mathbf{2 4 . 0 0}$ \\
\cline { 2 - 9 } Qaroun & 31.55 & 20.60 & 13.35 & 7.17 & 4.97 & 3.84 & 3.30 & 2.08 \\
Zahle & 17.36 & 13.76 & 10.52 & 6.92 & 5.70 & 4.97 & 4.48 & 3.27 \\
Reyak & 13.13 & 9.98 & 7.50 & 4.93 & 3.88 & 3.15 & 2.72 & 1.92 \\
Average & 19.12 & 13.46 & 11.40 & 7.01 & 4.68 & 3.60 & 3.12 & 1.99 \\
St, Dev. & $\mathbf{2 0 . 2 9}$ & $\mathbf{1 4 . 4 5}$ & $\mathbf{1 0 . 6 9}$ & $\mathbf{6 . 5 1}$ & $\mathbf{4 . 8 1}$ & $\mathbf{3 . 8 9}$ & $\mathbf{3 . 4 1}$ & $\mathbf{2 . 3 1}$ \\
\hline
\end{tabular}

\section{- Calculate the Intensity-Frequency Ratios}

The procedure to obtain the parameters $\mu \& \mathrm{~h}$ of equation (1.12), is described in the following 3 steps:

$$
f 2(T)=\frac{I_{d}^{T}}{I_{d}^{100 Y r s}}=(\mu * \ln T+\mathrm{h})
$$

- The average rainfall intensity $I_{d}^{T}$, for the five stations, were calculated for each duration, $(\mathrm{d}=15 \mathrm{~min}, 30 \mathrm{~min}$, $1 \mathrm{hr}, 3 \mathrm{hrs}, 6 \mathrm{hrs}, 12 \mathrm{hrs}, 18 \mathrm{hrs}$ and $24 \mathrm{hrs}$ ) at return periods $\mathrm{T}=2,5,10,25,50 \& 100$ years.

- Figure 1.5 shows the average rainfall intensity values at each return period versus the average rainfall intensity at 2-yr return period. The slope of each line is the Intensity-Frequency ratio at each recurrence interval, T. Table 1.5 shows the average ratios and standard deviations for each return period.

- $\quad$ Figure 1.6 represents that relationship between rainfall intensity (I) and Frequency (T) of the 5 stations through which the parameter $\mu=0.224$ (slope of linear regression relationship between the log-transformed values of return periods) and $h=0.863$ were obtained with correlation coefficient value $R^{2}=0.99$.

$$
f 2(T)=\frac{I_{d}^{T}}{I_{d}^{2 Y r s}}=(0.224 * \ln T+0.863)
$$

Table 1.5 Rainfall Intensity-Frequency Ratios $\frac{I_{24}^{T}}{I_{24}^{2}}$ average for all return periods

\begin{tabular}{lllllll}
\hline \multirow{2}{*}{ Station } & \multicolumn{7}{l}{ Return Periods - T Years } & & & & \\
\cline { 2 - 7 } Tyre & $\mathbf{2}$ & $\mathbf{5}$ & $\mathbf{1 0}$ & $\mathbf{2 5}$ & $\mathbf{5 0}$ & $\mathbf{1 0 0}$ \\
\cline { 2 - 7 } Lebaa & 1.00 & 1.19 & 1.32 & 1.48 & 1.60 & 1.72 \\
Qaroun & 1.00 & 1.24 & 1.40 & 1.60 & 1.75 & 1.89 \\
Zahle & 1.00 & 1.24 & 1.39 & 1.58 & 1.72 & 1.86 \\
Reyak & 1.00 & 1.23 & 1.39 & 1.58 & 1.73 & 1.87 \\
Average & 1.00 & 1.29 & 1.48 & 1.72 & 1.89 & 2.07 \\
St. Dev. & 1.00 & 1.24 & 1.39 & 1.59 & 1.74 & 1.88 \\
\hline
\end{tabular}




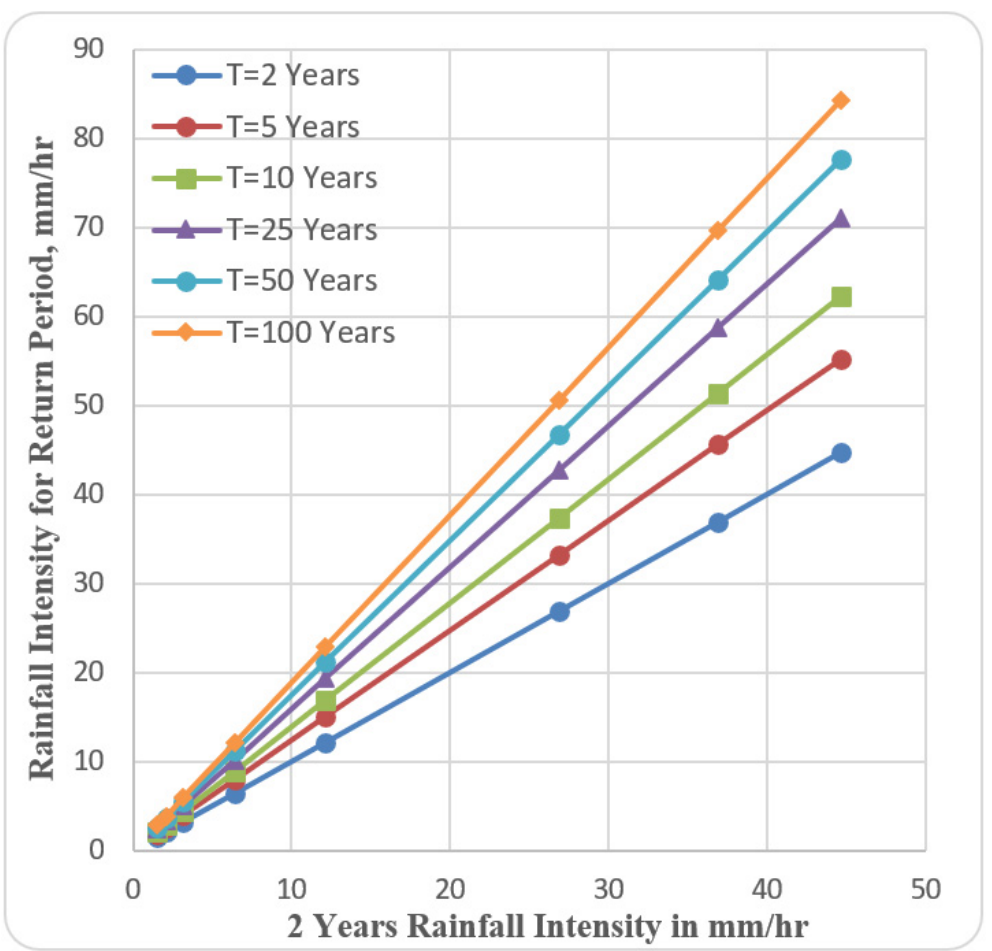

Figure 1.5 Rainfall Intensity-Frequency Ratios

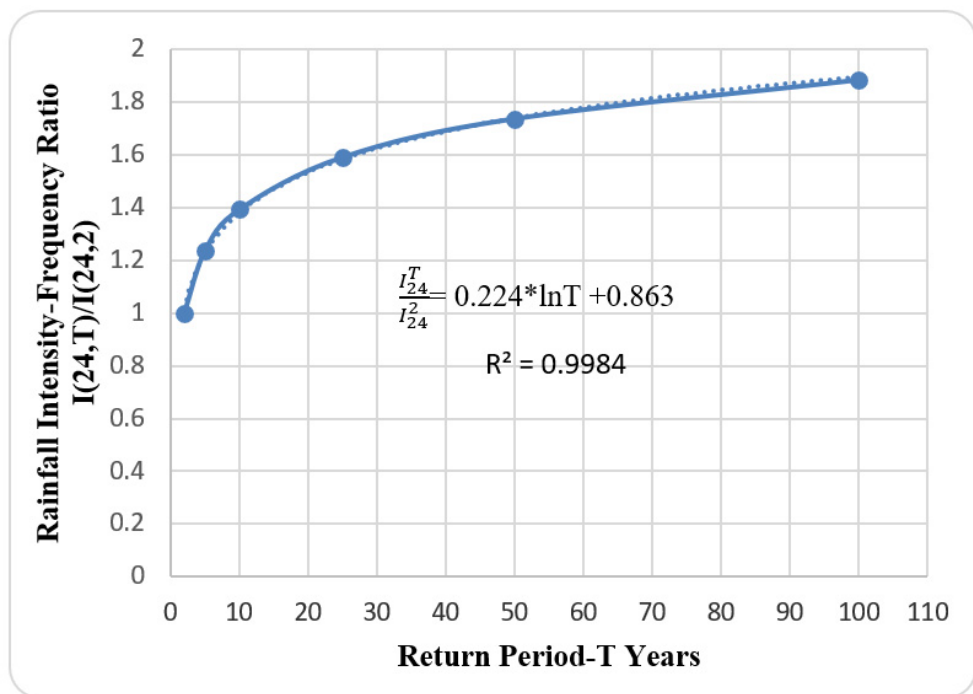

Figure 1.6 Rainfall Intensity-Frequency Ratios and Return periods. This graph was fitted by Bell generalized formula (1.12) to get the parameters $\mu \& \mathrm{~h}$.

\section{- Combining the Equations (Bell, Chen \& Sherman) in one General IDF Formula.}

After combining Equation (1.5) and (1.11) and (1.13), the generalized formula of rainfall intensity frequency based on $I_{24 h r}^{2 Y r s}$ rainfall intensity with 24-hours rainfall duration, and 2-year return period can be derived:

$$
I_{d}^{T}=I_{24-h r}^{2 Y r s} * \frac{a}{(d+b)^{c}} *(\mu \ln T+h)
$$


Since the intensity-duration and the intensity-frequency ratios obtained from 2 years' data are not fully representative for the ratios which Bell \& Chen equations were built on (more than 20 years of historical records), the obtained generalized formula, which is based on only 2 years' data, was considered to be correlated to the formula obtained in step 1 (based on 20 years daily records \& SCS Type II distribution) by 3 function as follows:

$$
I_{d}^{T}=\left[\mathrm{F} 1 * I_{24-h r}^{2 Y r s}\right]\left[\mathrm{F} 2 * \frac{a}{(d+b)^{c}}\right][\mathrm{F} 3 *(\lambda \ln T+C)]
$$

- $\quad \mathrm{F} 1=\frac{1}{\mathrm{n}} \sum_{\mathrm{i}}^{\mathrm{n}} \frac{\mathrm{I}_{24}^{100}}{\mathrm{I}_{24}^{2}}=1.88$ (average ratio of the five stations).

- $\quad \frac{\mathrm{A}}{(\mathrm{d}+\mathrm{B})^{\mathrm{C}}}=\mathrm{F} 2 * \frac{\mathrm{a}}{(\mathrm{d}+\mathrm{b})^{\mathrm{c}}}$

F2 can be simplified to linear relationship of two ranges as follows:

$0<\mathrm{d} \leq 1$ hour, $\mathrm{F} 2=3.5$

$1<\mathrm{d} \leq 24$ hours, $\mathrm{F} 2=0.9^{*} \frac{31.214}{(d-0.876)^{0.4605}}$

- $\quad(\lambda \ln T+H)=F 3 *(\mu \ln T+h)$

Using least square method, the correlation function F3 between both equations is linear, $\mathrm{F} 3=0.54$.

Therefore, the IDF formulas for the 5 stations, representing different climatic conditions based on $\mathrm{I}(\mathrm{d}=24$ hours, $\mathrm{T}=2$ Years), in Litani River Basin can be generalized as:

For $0<\mathrm{d} \leq 1$ hour

$$
I_{d}^{T}=3.5 * I_{24-h r}^{2 Y r s} * \frac{31.214}{(d-0.876)^{0.4605}} *(0.224 \ln T+0.863)
$$

For $1<\mathrm{d} \leq 24$ hours

$$
I_{d}^{T}=0.9 * \frac{31.214}{(d-0.876)^{0.4605}} * I_{24-h r}^{2 Y r s} * \frac{31.214}{(d-0.876)^{0.4605}} *(0.224 \ln T+0.863)
$$

\section{- Validation of the Generalized IDF Formula (Base Value $I_{24}^{100} \& I_{24}^{2}$ )}

As an example, Table 1.6 shows the comparison between intensity values, of Zahle Station, at different durations and return periods, derived using the equation of frequency analysis method and the values derived using the

\begin{tabular}{|c|c|c|c|c|c|c|}
\hline \multirow[b]{2}{*}{ 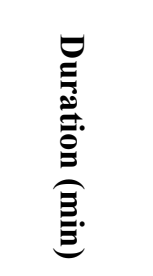 } & \multicolumn{3}{|c|}{$\mathbf{T}=\mathbf{2}$ Years } & \multicolumn{3}{|c|}{$\mathrm{T}=\mathbf{2 5}$ Years } \\
\hline & 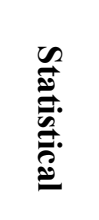 & 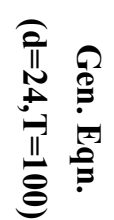 & 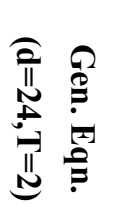 & 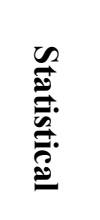 & 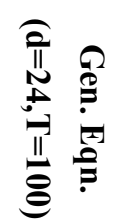 & 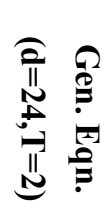 \\
\hline 15 & 37.79 & 38.06 & 39.14 & 59.17 & 58.95 & 60.89 \\
\hline 30 & 31.20 & 31.27 & 32.24 & 48.87 & 48.45 & 50.14 \\
\hline 60 & 22.69 & 22.81 & 23.54 & 35.55 & 35.33 & 36.61 \\
\hline 180 & 10.28 & 10.44 & 10.65 & 16.10 & 16.17 & 16.57 \\
\hline 360 & 5.42 & 5.48 & 5.59 & 8.48 & 8.48 & 8.70 \\
\hline 720 & 2.68 & 2.66 & 2.66 & 4.20 & 4.12 & 4.13 \\
\hline 1080 & 1.75 & 1.71 & 1.64 & 2.74 & 2.64 & 2.56 \\
\hline 1440 & 1.29 & 1.24 & 1.15 & 2.02 & 1.91 & 1.79 \\
\hline МАРЕ\% & & $1.44 \%$ & $4.38 \%$ & & $1.63 \%$ & $4.19 \%$ \\
\hline
\end{tabular}
generalized IDF formulas based on intensities I (24hrs, 100 Yrs) \& I (24hrs, 2 Yrs).

Table 1.6 Comparison between intensity values using different equations at Zahle Station 
Figure 1.7 shows the MAPE (Mean Absolute Percentage Error) for Generalized IDF equation based on I (24hours, 100 years) \& Generalized IDF equation based on I (24hours, 2 years) compared to intensities obtained by statistical frequency analysis method (Kimijima Equation).

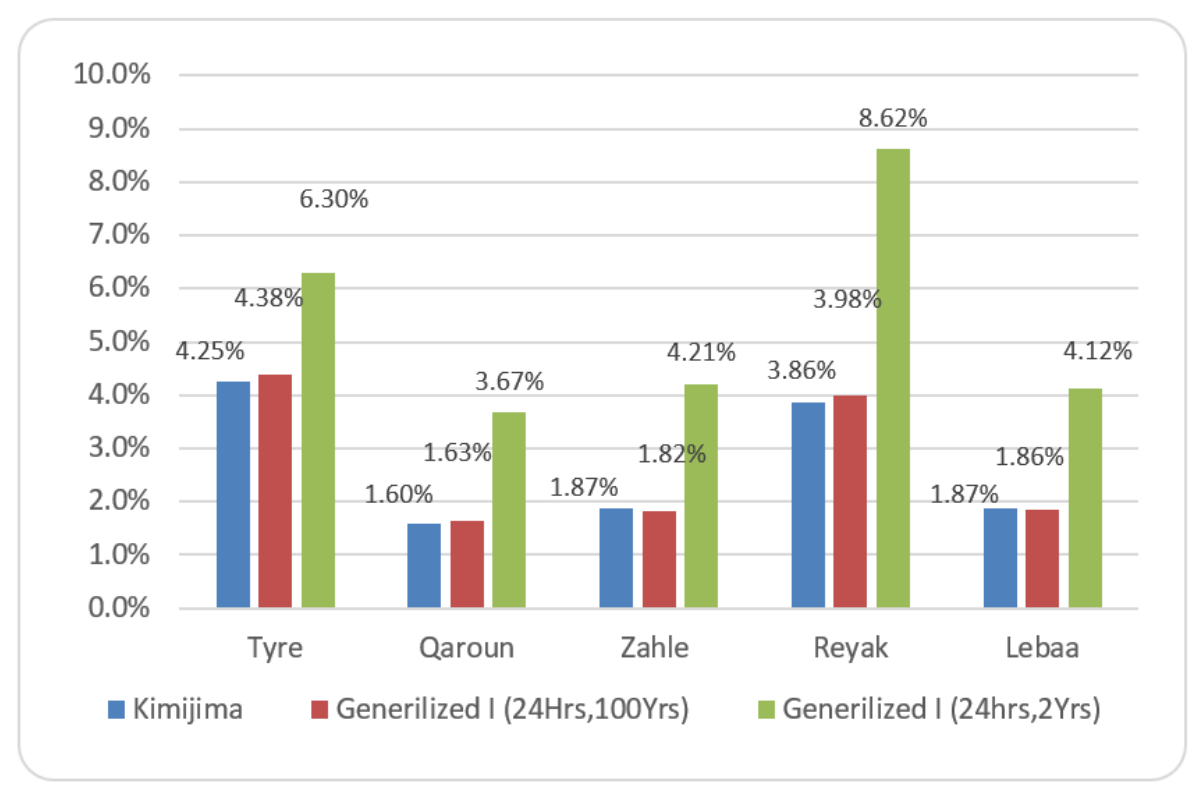

Figure 1.7 Mean Absolute Percentage Error at each station

As an example, Figures $1.8(\mathrm{a}, \mathrm{b} \& \mathrm{c}$ ) are the Intensity-Duration-Frequency curves of Reyak Station using the three methods: Statistical Frequency Analysis, Generalized Equation based on I (24hrs, $100 \mathrm{yrs})$ and Generalized Equation based on I (24hrs, 2 yrs).

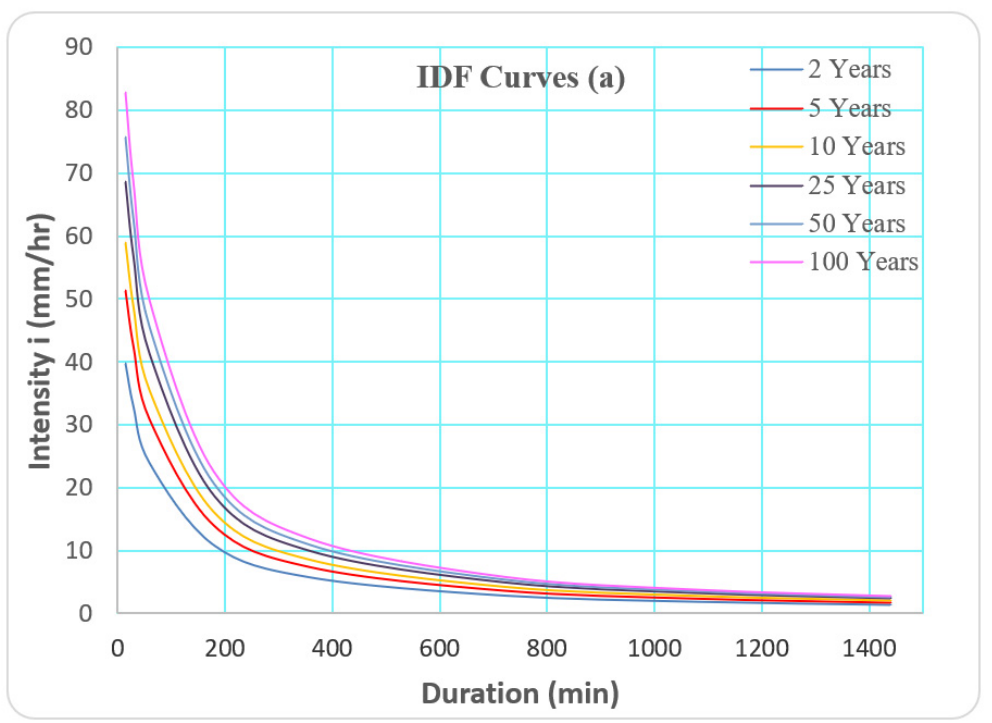



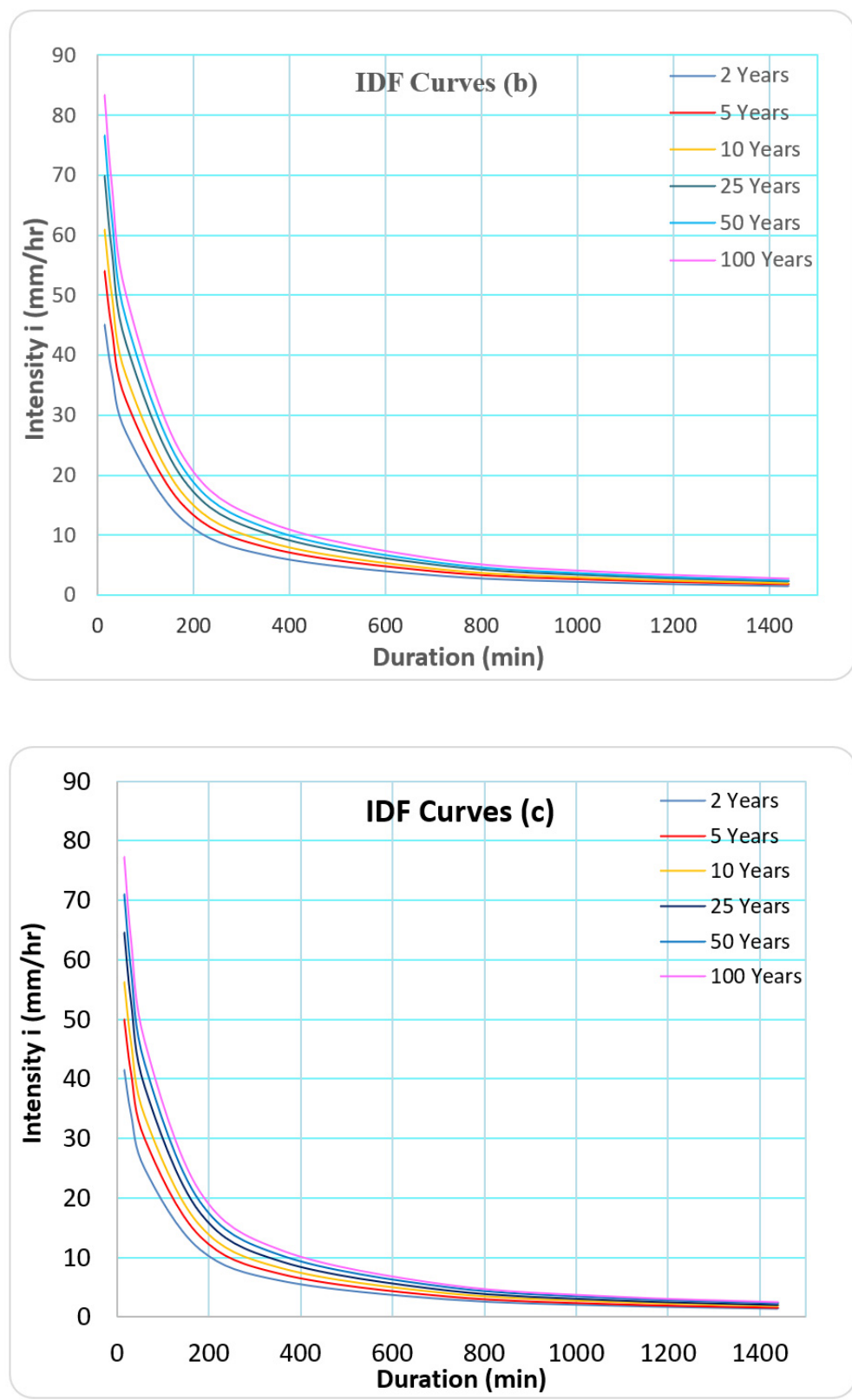

Figure 1.8 IDF-Curves at Reyak Weather Station using: a) Statistical Frequency Analysis, b) Generalized Formula based on $I_{24}^{100} \&$ c) Generalized Formula based on $I_{24}^{2}$.

\section{Conclusion}

- Since Litani River Basin compromise all the climatological weather condition, and based on the validation results above, it can be concluded that the Generalized IDF Formula $I_{d}^{T}=$ $I_{24-h r}^{100 Y r s} \frac{5470}{(d+68.06)^{1.182}}(0.1182 \ln T+0.4619) \quad$ can be used in other ungauged watersheds of Lebanon with acceptable percentage of error.

- The weaknesses of this method are the large number of parameters involved in the methodology, and the calculation of a regression based on dependent values since the estimated quantiles of sub-hourly and hourly ratios have been disaggregated using SCS Type II rainfall distribution. 
- The derivation of generalized IDF formula based on only 3 years of sub-hourly and hourly rainfall data is unique in this research and beneficial for developing IDF-Curves in developing countries where historical hourly rainfall data are not yet available.

- In this respect, it can be believed that Continues collection of sub-hourly \& hourly rainfall data at incremental steps through the installed tipping bucket rainguages will be valuable and beneficial for future calibration and improvement for both the IDF curves established by statistical method and the generalized IDF formula as well.

\section{Acknowledgment}

Authors are indebted to the Beirut Airport Weather Forecast Department, Lebanese Agricultural Research Institute (LARI) and National Council for Scientific Researches (CNRS) for providing the necessary meteorological data and GIS (Geographic Information System) database.

\section{References}

Bell, F. C. (1969). Generalized rainfall-duration-frequency relationships, Journal of the Hydraulics Division, 95(1), 311-327. https://doi.org/10.1061/JYCEAJ.0001942

Bernard, M. M. (1932). Formulas for Rainfall Intensities of Long Durations. Transactions. ASCE, 96, 592-624. https://doi.org/10.1061/TACEAT.0004323

Chen, C. L. (1983). Rainfall intensity-duration-frequency formulas, Journal of Hydraulic Engineering, 109(12), 1603-1621. https://doi.org/10.1061/(ASCE)0733-9429(1983)109:12(1603)

Chow, V. T., Maidment, D. R., Mays, L. W. (1998). Applied Hydrology, McGraw-Hill.

Hamzeh, H. R. (2012). Climate effects on the Litani basin watershed in Lebanon.

Hosking, J. R. M., \& J. R. Wallis (1997). Regional Frequency Analysis, Cambridge Univ. Press, New York. https://doi.org/10.1017/CBO9780511529443

Kothyari, U. C., \& Grade, R. J. (1992). Rainfall intensity duration frequency formula for India. Journal of Hydr. Engrg., ASCE, 118(2), 323-336. https://doi.org/10.1061/(ASCE)0733-9429(1992)118:2(323)

Koutsoyiannis, D., Kozonis, D., Manetas, A. (1998). A mathematical framework for studying rainfall intensityduration frequency relationships. J. Hydrol. 206, 118-135. https://doi.org/10.1016/S0022-1694(98)00097-3

Maidment, D. R. (1993). Handbook of Hydrology, McGraw-Hill.

Nhat, L. M., Tachikawa, Y., \& Takara, K. (2006a). Establishment of Intensity-Duration- Frequency curves for precipitation in the monsoon area of Vietnam, Annuals of Disas. Prev. Res. Inst., Kyoto Univ., No. 49B.

Nhat, L. M., Tachikawa, Y., Sayama, T., \& Takara, K. (2006b). Generalized IDF for Precipitation in the Monsoon Areas, Proc. of the 7th Inter. Workshop on Precipitation in Urban Areas, St. Moritz, Switzerland, 180-184.

Raghunah, H. M. (2006). Hydrology"Principles, Analysis, Design"- 2nd Edition.

Sherman, C. W. (1932). Frequency and Intensity of Excessive Rainfalls at Boston-Massachusetts. Transactions, ASCE, 95, 951-960. https://doi.org/10.1061/TACEAT.0004286

United States Agency for International Development (USAID). (2011). Litani River Basin Management Support Program.

\section{Copyrights}

Copyright for this article is retained by the author(s), with first publication rights granted to the journal.

This is an open-access article distributed under the terms and conditions of the Creative Commons Attribution license (http://creativecommons.org/licenses/by/4.0/). 